\title{
How Taxes and Spending on Education Influence Economic Growth in Poland
}

\author{
Michał Konopczyński ${ }^{1}$
}

ABSTRACT

\begin{abstract}
This paper investigates the relationship between economic growth in Poland and four types of taxes and human capital investment. We primarily rely on an exogenous growth model that merges the Mankiw-Romer-Weil model, augmented with learning-by-doing and spillover-effects, with selected elements from the literature on optimal taxation. We demonstrate that in the period 20002011, economic growth in Poland was primarily due to a rapid increase in the human capital stock (at a rate of $5 \%$ per annum) and only secondarily due to the accumulation of productive capital (2.7\% annually). Simulations of tax cuts suggest that income taxes and consumption taxes restrict economic growth equally heavily. Simultaneously reducing all tax rates by 5 percentage points (pp) in Poland should increase annual GDP growth by approximately 0.4 pp. Increasing spending on education by 1 pp of GDP would increase the growth rate by approximately $0.3 \mathrm{pp}$.
\end{abstract}

KEY WORDS: $\quad$ fiscal policy; income taxes; labor taxes; capital taxes; VAT; economic growth; human capital

JEL Classification: $\quad$ E62; $\mathrm{H} 21 ; \mathrm{H} 52$

${ }^{1}$ Poznań University of Economics, Poland

\section{Introduction}

The standard approach in modern growth theory is to describe the savings and consumption decisions of households as an intertemporal optimization problem. However, in our view, in the case of Central and Eastern European (CEE) countries, the calibration (or estimation) of such models would be difficult for several reasons. First, to the best of our knowledge, there are no reliable empirical estimates of the parameters of the intertemporal utility function for most CEE countries. Second, optimal control models assume that economic agents are consistently optimizing, adjusting control

Correspondence concerning this article should be addressed to: Michał Konopczyński, Poznań University of Economics, al. Niepodległości 10, 61-875 Poznań, Poland. tel. 48618543932 fax: 48618543672 Email: michal.konopczynski@ue.poznan.pl ('jump’) variables (e.g., savings and consumption) in response to policy changes. In our view, it would be overly optimistic (unjustified) to assume that CEE economies are already in this type of equilibrium. These countries remain in transition from centrally planned, Eastern-oriented economies to market-based economies integrated with the West (the EU). Moreover, over the last 20 years, the CEE economies have experienced intense structural changes coupled with significant changes in economic policies. Furthermore, external conditions have also rapidly evolved, with the expansion of the EU in 2004 arguably representing the greatest (revolutionary) change.

For the above reasons, our analysis is deliberately based on a simple exogenous growth model, with numerous elements borrowed from the Mankiw-Romer-Weil (1992) growth model. For example, we incorporate the power production function with constant economies of scale and exogenous rates of investment and savings. We 
also conceptualize human capital as a stock that requires investment and depreciates over time. (A thorough review of human capital research is presented by Cichy (2008) and Acemoglu (2008).) Furthermore, mathematical rules describing the public sector are taken from the literature on optimal fiscal policy; see (e.g., Agenor, 2007; Dhont \& Heylen, 2009; Lee \& Gordon, 2005). Four types of taxes are considered: taxes on capital, labor, human capital and consumption. The tax revenues are expended on public consumption and human capital investment, and the remainder is transferred back to households. The government budget is permanently balanced, which is a standard assumption in most research on optimal fiscal policy, initiated by Barro (1990), and developed in numerous subsequent studies, including the abovementioned Lee \& Gordon (2005), Agenor (2007), Dhont and Heylen (2009). The assumption of a balanced budget is fully justified for closed economy models (as in our paper) by the well-known effect of Ricardian equivalence. However, in light of recent empirical data, such an assumption may appear unrealistic. Therefore, in the near future, we intend to generalize the model presented here by allowing the government to borrow both internally and from abroad. A simple example of such a model with perfect capital mobility was presented by Konopczyński (2013). The paper is organized as follows. Section 1 presents the benchmark private economy model. In section 2 , this model is augmented with a government that collects four types of taxes and invests in education. Section 3 contains a qualitative sensitivity analysis. In section 4 , we calibrate the model on the basis of statistical data on the Polish economy in the period 2000 - 2011. In section 5 , we present the baseline scenario, corresponding to the results of the calibration exercise. Sections 6 - 9 present scenarios analyzing tax cuts and increased educational expenditures by both the government and the private sector. The concluding section synthesizes the main results. Mathematical proofs are included in the appendix.

\section{The private economy}

The aggregate output of the country is described by the following production function:

$Y=a K^{\alpha} H^{1-\alpha-\beta}(E)^{\beta}$,

where $K$ denotes the stock of physical capital, $H$ represents the stock of human capital, and $L$ is raw labor. We assume positive externalities related to learning-bydoing and spillover-effects; see, e.g., Romer (1986) and Barro and Sala-i-Martin (2004). These externalities are reflected in the labor-augmenting technology index $E$, which is proportional to the capital per worker ratio, i.e., $E=x K / L$, where $x=$ const. $>0$. Thus, the production function can be written as

$Y=A K^{\alpha+\beta} H^{1-\alpha-\beta}$,

where $A=a x^{\beta}=$ const $>0$. Therefore, aggregate output in the economy is described by a Cobb-Douglas function with constant returns to scale for both types of capital (physical and human). The assumption of constant returns to scale is supported by strong empirical evidence. See, e.g., (Balisteri, McDaniel, \& Wong, 2003; Cichy, 2008; Mankiw, Romer, \& Weil, 1992; Manuelli \& Seshadri, 2005; Próchniak, 2013; Willman, 2002). Nevertheless, we note that by considering increasing or decreasing returns to scale, our analysis could lead to different conclusions.

We assume that the labor supply in the country is growing exponentially:

$L=L_{0} e^{n t}$

where $L_{0}>0$ denotes the initial stock of labor (at $t=0$ ), whereas $t \geq 0$ is a continuous time index. Demand for all three factors of production results from the rational decisions of firms maximizing profits in perfectly competitive markets. Let $w_{K}$ and $w_{H}$ denote the real rental price of physical capital and human capital, respectively, and let $w$ denote the real wage rate. In the profit maximizing equilibrium, all three factors are paid their marginal products, i.e.,

$$
\begin{aligned}
& M P K=\partial Y / \partial K=\alpha Y / K=w_{K}=r+\delta_{K}, \\
& M P H=\partial Y / \partial H=(1-\alpha-\beta) Y / H=w_{H}, \\
& M P L=\partial Y / \partial L=\beta Y / L=w
\end{aligned}
$$

Obviously, in equilibrium, the real rental rate of physical capital is equal to the sum of the real interest rate $r$ and the rate of depreciation $\delta_{K}$. We assume that a constant, exogenous fraction of national income is saved: $S=\gamma \cdot Y$, where $0<\gamma<1$. Savings are invested 
in physical and human capital, with a fixed share coefficient $0<\psi<1$ :

$I_{K}=(1-\psi) \cdot S$,

$I_{H}=\psi S$,

The accumulation equations are:

$\dot{K}=I_{K}-\delta_{K} K, \quad 0<\delta_{K}<1$,

$\dot{H}=I_{H}-\delta_{H} H, \quad 0<\delta_{H}<1$,

where $\delta_{K}$ and $\delta_{H}$ denote depreciation rates. Throughout the text, a dot over the symbol for a variable denotes the time derivative, e.g., $\dot{K}=\partial K(t) / \partial t$.

\section{Proposition 1. (proof in the Appendix)}

In the long run, the private economy converges towards the balanced growth path, with $K, H$ and $Y$ growing at the same, constant rate (the balanced growth rate, BGR). This balanced growth equilibrium is unique and globally asymptotically stable. The BGR cannot be determined analytically. It can only be identified numerically by solving a particular non-linear equation. Despite this difficulty, it is possible to prove that the BGR is an increasing function of the rate of savings $\gamma$ and a decreasing function of both depreciation rates. Most important, the relationship between the BGR and the share coefficient $\psi$ is ambiguous.

\section{The economy with the government investing in human capital}

Now, we augment the above model by introducing the public sector (hereafter referred to as the government), which levies income and consumption taxes and invests in human capital.

The optimality conditions (6) - (8) remain valid, but the variables $w, w_{H}$ and $w_{K}=r+\delta_{K}$ hereafter represent gross rates, i.e., the unit costs of labor, human capital and physical capital from the perspective of the representative firm. Let $\tau_{L}, \tau_{H}$, and $\tau_{K}$ denote the average tax rates. Taxes on labor and human capital are levied on gross wage rates, i.e., the government collects $\tau_{L} w$ and $\tau_{H} w_{H}$. The income tax on capital is calculated as follows: $\tau_{K}\left(w_{K}-\delta_{K}\right)=\tau_{K} r$, i.e., the tax is levied on net capital income, defined as gross income minus a depreciation allowance. The total sum of all income taxes is expressed as

$T_{1}=\tau_{L} w L+\tau_{H} w_{H} H+\tau_{K} r K$,

In addition, the government collects consumption taxes equal to

$T_{2}=\tau_{C} C$,

where $C$ is aggregate consumption. Total government revenue is $T=T_{1}+T_{2}$. For simplicity, the government is assumed to maintain a balanced budget in each period, i.e., $G=T$. This assumption is justified by Ricardian equivalence - see, for example, Elmendorf and Mankiw (1998), and it is commonly applied in the literature; see for example Lee \& Gordon (2005), Dhont \& Heylen (2009), and Turnovsky (2009). Public expenditures include three components:

$G=G_{T}+G_{E}+G_{C}$,

where $G_{T}$ denotes cash transfers to the private sector (primarily social transfers, i.e., pensions, various benefits, social assistance, etc.), $G_{E}$ represents public spending on education, and $G_{C}$ is public consumption (primarily health care, national defense, and public safety). By assumption, transfers and expenditures on education are proportional to GDP:

$G_{T}=\gamma_{T} \cdot Y, \quad$ where $\quad 0<\gamma_{T}<1$

$G_{E}=\gamma_{E} \cdot Y, \quad$ where $\quad 0<\gamma_{E}<1$.

In a closed economy, the total compensation of all production factors is equal to output. Therefore, households' disposable income $Y_{d}$ is equal to GDP net of taxes, plus transfers. A fraction of that income is saved, and the remainder is consumed; hence the budget constraint of the private sector is expressed as follows:

$Y_{d}=Y-T_{1}-T_{2}+G_{T}=C+S$.

We assume a constant, exogenous rate of savings:

$S=\gamma Y_{d}=\gamma\left(Y-T_{1}-T_{2}+G_{T}\right)$ 
Savings are invested in physical and human capital, with a fixed coefficient $\psi$, according to equations (9) and (10). From (18), it follows that private consumption is equal to:

$C=Y_{d}-S=Y-T_{1}-T_{2}+G_{T}-S$.

Notice that equations (19) and (20) are interconnected because of (14). According to (19), savings depend on consumption, and simultaneously, according to (20) consumption depends on savings. For convenience, we solve this system of equations. Simple algebraic manipulation yields:

$C=A_{1} \cdot\left(Y-T_{1}+G_{T}\right)$, where $A_{1}=\frac{1-\gamma}{1+\tau_{C}(1-\gamma)}$

$S=A_{2} \cdot\left(Y-T_{1}+G_{T}\right)$, where $A_{2}=\frac{\gamma}{1+\tau_{C}(1-\gamma)}$

Henceforth, for simplicity, certain expressions (functions of parameters) will be denoted by $A_{1}, A_{2}$, etc. Substituting (13) and (16), and using (6) - (8), equation (22) can be written as:

$S=A_{2} \cdot\left[\left(1-\alpha \tau_{K}-\beta \tau_{L}-(1-\alpha-\beta) \tau_{H}+\gamma_{T}\right) Y+\tau_{K} \delta_{K} K\right]$.

From equations (19), (9), (10) and (23), it follows that:

$I_{H}=\psi S=\psi A_{2} \cdot\left[\left(1-\alpha \tau_{K}-\beta \tau_{L}-(1-\alpha-\beta) \tau_{H}+\gamma_{T}\right) Y+\right.$

$\left.+\tau_{K} \delta_{K} K\right]$.

$I_{K}=(1-\psi) \cdot S=(1-\psi) A_{2} \cdot\left[\left(1-\alpha \tau_{K}-\beta \tau_{L}-(1-\alpha-\beta) \tau_{H}+\right.\right.$ $\left.\left.+\gamma_{T}\right) Y+\tau_{K} \delta_{K} K\right]$.

The dynamic equations for physical and human capital are of the form:

$\dot{K}=I_{K}-\delta_{K} K, \quad 0<\delta_{K}<1$,

$\dot{H}=G_{E}+I_{H}-\delta_{H} H, \quad 0<\delta_{H}<1$.

Dividing both sides of these equations by $K$ and $H$ (respectively) yields the following growth rates:

$\hat{K}=\frac{\dot{K}}{K}=\frac{I_{K}}{K}-\delta_{K}$,

$\hat{H}=\frac{\dot{H}}{H}=\frac{G_{E}+I_{H}}{H}-\delta_{H}$
Substituting (25), equation (28) can be transformed into the following form:

$\hat{K}=(1-\psi) A_{2} A_{3} \frac{Y}{K}+A_{4}$,

where

$A_{3}=1-\alpha \tau_{K}-\beta \tau_{L}-(1-\alpha-\beta) \tau_{H}+\gamma_{T}$,

$A_{4}=\left[(1-\psi) A_{2} \tau_{K}-1\right] \delta_{K}$,

Similarly, using (17) and (24) in equation (29) yields:

$\hat{H}=A_{5} \frac{Y}{H}+A_{6} \frac{K}{H}-\delta_{H}$,

where

$A_{5}=\gamma_{E}+\psi A_{2} A_{3}$

$A_{6}=\psi A_{2} \tau_{K} \delta_{K}$,

Finally, using (4), the growth rates (30) and (33) can be written as:

$\hat{K}=(1-\psi) A_{2} A_{3} A\left(\frac{K}{H}\right)^{\alpha+\beta-1}+A_{4}$,

$\hat{H}=A_{5} A\left(\frac{K}{H}\right)^{\alpha+\beta}+A_{6} \frac{K}{H}-\delta_{H}$.

\section{Proposition 2 (proof in the Appendix)}

In the long run, the economy converges towards the balanced growth path, with $K, H$ and $Y$ growing at the same, constant rate (the balanced growth rate, BGR). This balanced growth equilibrium is unique and globally asymptotically stable.

In equilibrium, it holds that $\hat{Y}=\hat{H}=\hat{K}$. Thus, the BGR can be obtained by equating the righthand sides of equations (36) and (37). The resulting equation (except for certain special cases) cannot be solved analytically - it can only be solved numerically, after substituting certain values for all parameters. Although it is not possible to derive an explicit formula for the BGR, it is perfectly possible (and worthwhile) to perform a qualitative sensitivity analysis to determine the relationship between the parameters of the model and the BGR. 
Table 1. Qualitative sensitivity analysis

\begin{tabular}{|c|c|c|c|c|c|c|c|c|}
\hline & $\tau_{K} \uparrow$ & $\tau_{H} \uparrow$ & $\tau_{L} \uparrow$ & $\tau_{C} \uparrow$ & $\gamma \uparrow$ & $\gamma_{T} \uparrow$ & $\gamma_{E} \uparrow$ & $\psi \uparrow$ \\
\hline$A_{2}$ & $=$ & $=$ & $=$ & $\downarrow$ & $\uparrow$ & $=$ & $=$ & $=$ \\
\hline$A_{3}$ & $\downarrow$ & $\downarrow$ & $\downarrow$ & $=$ & $=$ & $\uparrow$ & $=$ & $=$ \\
\hline$A_{4}$ & $\uparrow$ & $=$ & $=$ & $\downarrow$ & $\uparrow$ & $=$ & $=$ & $\downarrow$ \\
\hline$A_{5}$ & $\downarrow$ & $\downarrow$ & $\downarrow$ & $\downarrow$ & $\uparrow$ & $\uparrow$ & $\uparrow$ & $\uparrow$ \\
\hline$A_{6}$ & $\downarrow$ & $=$ & $=$ & $\downarrow$ & $\uparrow$ & $=$ & $=$ & $\uparrow$ \\
\hline $\begin{array}{l}\text { graphof } \\
K(K / H)\end{array}$ & $?$ & $\downarrow$ & $\downarrow$ & $\downarrow$ & $\uparrow$ & $\uparrow$ & $=$ & $\downarrow$ \\
\hline $\begin{array}{l}\text { graph of } \\
H(K / H)\end{array}$ & $?$ & $\downarrow$ & $\downarrow$ & $\downarrow$ & $\uparrow$ & $\uparrow$ & $\uparrow$ & $\uparrow$ \\
\hline BGR & $?$ & $\downarrow$ & $\downarrow$ & $\downarrow$ & $\uparrow$ & $\uparrow$ & $\uparrow$ & $?$ \\
\hline
\end{tabular}

\section{Qualitative sensitivity analysis}

In this section, we wish to determine how changes in parameter values influence the BGR. Specifically, we account for all (four) tax rates, the rate of private savings $\gamma$, the rate of public transfers $\gamma_{T}$, the rate of spending on education $\gamma_{E}$, and the share coefficient $\psi$. The analysis is performed in 3 steps. First, we investigate whether an increase in the value of a parameter increases or reduces the values of expressions $A_{2}, \ldots, A_{6}$. Second, using formulas (36) and (37), we investigate whether the graphs of functions $\hat{K}(K / H)$ and $\hat{H}(K / H)$ shift up or down. Third, based on these observations, we conclude whether the intersection of these curves, which corresponds to the BGR (see Appendix, fig. A2), moves up or down. The results are summarized in table 1 .

Notice that increasing any tax rate reduces the BGR, with one noticeable exception. The effect of raising the tax rate on capital is ambiguous, as without additional assumptions, we cannot determine whether the graphs of $\hat{H}(K / H)$ and $\hat{K}(K / H)$ shift up or down.

It is unsurprising that the higher the rate of private savings $\gamma$, the higher the BGR. Similarly, there is a positive relationship between the rate of public spending on education $\gamma_{E}$ and the BGR. The positive relationship between the BGR and the rate of financial transfers to the private sector $\gamma_{T}$ requires explanation. Due to the assumption of a permanently balanced government budget, higher transfers to the private sector (with no change in taxes) are automatically offset by reduced public consumption, with no change in public spending on education. These structural changes result in higher disposable income in the private sector. Therefore, private investment in education and physical capital increases, whereas public spending on education remains unchanged. The total effect is unambiguous - the BGR increases.

The effect of increasing the share parameter $\psi$ is quite interesting. Recall that $\psi$ represents the share of private savings invested in education. Therefore, increasing $\psi$ raises the rate of human capital accumulation and simultaneously reduces the rate of physical capital growth. Technically, the graph of $\hat{H}(K / H)$ shifts up, whereas the graph of $\hat{K}(K / H)$ shifts down (see Appendix, fig. A2). The intersection of these curves unambiguously moves to the left, but it is uncertain whether it moves up or down. Therefore, a higher value of $\psi$ reduces the balanced growth ratio of $\bar{K} / \bar{H}$ - there is more human capital per each unit of physical capital. However, the relationship between $\psi$ and the BGR is ambiguous. 
Based on table 1, we can formulate the following.

\section{Proposition 3}

First, the balanced growth rate (BGR) is an increasing function of the rate of private savings $\gamma$, the rate of public transfers $\gamma_{T}$, and the rate of public spending on education $\gamma_{E}$. Second, the BGR is a decreasing function of the tax rates on labor, human capital and consumption. Third, the relationship between the BGR and the tax rate on capital income, as well as the share coefficient (the percentage of private savings invested in education), is ambiguous.

These qualitative results, though interesting per se, only enhance our desire for quantitative results. Moreover, as the BGR cannot be determined analytically, it is not possible to determine how strongly changes in the values of parameters influence the BGR. Simply, we know the direction of the effect, but we know nothing of the size of the effect. Answering these questions is not possible without establishing (estimating or calibrating) certain (benchmark) parameter values and performing numerical analyses. Achieving these outcomes is possible for any country or group of countries. In our view, Poland represents an interesting case - it experienced tremendous growth in education over the past 20 years, coupled with a substantial increase in physical capital. Both of these factors contributed to rapid (and relatively stable) economic growth. In what follows, we calibrate the model for Poland and numerically analyze optimal fiscal policy, as well as optimal private sector parameters. The calibration is based on macroeconomic data for Poland for the period 2000 2011, published by the Eurostat, OECD, and the Kiel Institute for the World Economy.

\section{Model calibration for Poland}

\section{Technological parameters}

The elasticities of the production function (2) have been estimated in numerous empirical papers; see, (e.g., Cichy, 2008; Mankiw, et al., 1992; Manuelli \& Seshadri, 2005; Próchniak, 2013). They are typically close to $1 / 3$; hence we set: $\alpha=\beta=1-\alpha-\beta=1 / 3$. The rate of physical capital depreciation is difficult to estimate for Poland, due to its economic transformation and massive stock of useless machinery, infrastructure, etc. inherited from the centrally 'planned' economy. In various research papers, physical capital depreciation varies from approximately $3.5 \%$ to $7 \%$. As the focus of our analysis is on the long-run equilibrium, we set the depreciation rate at a relatively low level of $\delta_{K}=4 \%$, following Nehru \& Dhareshwar (1993). The rate of human capital depreciation has been estimated by Manuelli \& Seshadri (2005), Arrazola \& de Hevia (2004) and others. Following these authors, we set $\delta_{H}=1.5 \%$.

Next, we must estimate the real rate of return on capital $(r)$. From (6), it follows that $r=\alpha \cdot Y / K-\delta_{K}$ (if firms maximize profits, which we assume). The ratio of $Y / K$ is very difficult to estimate for Poland, as (to the best of our knowledge) there are no data on the stock of productive capital in Poland. The Polish Main Statistical Office only registers "gross value of fixed assets", which is a far narrower category than "productive capital". This situation becomes obvious when consider the useful data collected by the Kiel Institute for the World Economy in the "Database on Capital Stocks in OECD Countries". It contains capital stock estimates for 22 OECD countries for the period 1960-2001. Poland is not included. For the 22 countries that are included, the average ratio of capital to GDP was very close to 3 throughout the period 1960-2001 - it varies between 2.9 and 3.3. In certain countries it was slightly lower, e.g., for the U.S., Canada, and the United Kingdom, it was close to 2.5. In most of continental Europe, however, it is close to 3 or slightly higher, e.g., for Germany, Switzerland and Greece, it is approximately 3.5. Generally, these ratios are very close to generally accepted stylized facts.

However, there is an issue regarding the case of Poland. If we employ the data provided by the Polish Main Statistical Office and calculate the ratio of "gross value of fixed assets" to GDP, it is approximately 1.71.8. Clearly, the data available for Poland only reflect a share of all productive capital. To the best of our knowledge, there are no data available for Poland that would better satisfy our requirements. Therefore, as a reasonable calibration, we will use the average ratio from the Kiel database, i.e., we set $Y / K=1 / 3$. (In the appendix, we present the sensitivity analysis, assuming higher and lower $Y / K$ values.) Substituting this number into (6) yields the real rate of return on capital equal to $r=1 / 3 \cdot 1 / 3-0.04=7.1 \%$. This result is very similar to most empirical estimates for OECD countries. For example, Campbell, Diamond \& Shoven 
(2001) report that the average real rate of return on stocks in the U.S. over the period 1900 - 1995 is 7\%. Similar indicators for the Polish stock market exist; however, Poland's stock market has only existed for approximately 23 years, and most of that period should be regarded as one of intense transformation and privatization of the economy. Thus, in our view, Polish stock market indicators do not reflect the long-run equilibrium and cannot be used to calibrate our model.

\section{Social transfers and the rates of savings and investment}

According to Eurostat, cash transfers to the private sector (primarily social transfers, i.e., pensions, various benefits, social assistance, etc.) were on average equal to $15.5 \%$ of GDP over the period 2000-2011. Thus, we set $\gamma_{T}=15.5 \%$.

The average rate of savings can be calibrated on the basis of equation (19), which can be transformed into the following formula:

$\gamma=\frac{S}{Y_{d}}=\frac{I_{K}+I_{H}}{Y-T+G_{T}}=\frac{I_{K} / Y+I_{H} / Y}{1-T / Y+G_{T} / Y}$.

According to Eurostat, gross fixed capital formation in Poland in the period 2000-2011 was on average 20,1\% of GDP. Moreover, private spending on education in the period 2000-2009 (the latest data available form Eurostat) was on average $0.62 \%$ of GDP. The ratio of 'total receipts from taxes and social contributions' to GDP in 2000-2011 was equal to $32.7 \%$ (and very stable). Substituting these numbers into (38) yields

$\gamma=\frac{I_{K} / Y+I_{H} / Y}{1-T / Y+G_{T} / Y}=\frac{20,1 \%+0,62 \%}{1-32,7 \%+15,5 \%}=25.02 \%$.

The share parameter $\psi$ can be directly calculated from equation (10):

$\psi=\frac{I_{H}}{S}=\frac{I_{H} / Y}{I_{K} / Y+I_{H} / Y}=\frac{0.62 \%}{20.1 \%+0.62 \%}=2.9 \% .(40)$

Clearly, in Poland, a mere 3\% of private savings is invested in education. (It is possible that private spending on education is underestimated in official statistics - a substantial share of it is likely classified as consumption, e.g., the cost of accommodation, travel, books, etc.). However, public outlays on education in Poland during the period 2002-2010 were on average equal to $5.84 \%$ of GDP (Eurostat); hence based on formula (18), we set $\gamma_{E}=5.84 \%$. In the same period, consumption taxes were equal to $12.1 \%$ of GDP. Thus, the ratio of income taxes to GDP is equal to $T_{1} / Y=T / Y-T_{2} / Y=32.7 \%-12.1 \%=20.6 \%$.

\section{Average tax rates}

Eurostat reports 'implicit tax rates' on capital, labor and consumption. In Poland during the period 20002010 (the latest data), these rates were on average equal to: $\tau_{K}=21.2 \%, \tau_{L}=32.8 \%$, and $\tau_{C}=19.4 \%$, respectively. Note that the implicit tax rate on labor is defined as the "Ratio of taxes and social security contributions on employed labor income to total compensation of employees". To the best of our knowledge, there are no data on the average tax rates on human capital. However, certain research papers provide valuable indications, (e.g., Gordon \& Tchilinguirian, 1998; Heckman \& Jacobs, 2010). These authors note the strong correlation between the level of education (human capital) and individual income. Therefore, in countries with highly progressive taxes on personal income, tax rates on human capital must be higher than tax rates on (raw) labor. Apart from these types of general (and obviously correct) indications, the literature provides virtually no methods for measuring average tax rates on human capital. Fortunately, we can obtain valuable information from the OECD Tax Database, which contains average tax rates on wages (precisely: "the average personal income tax and social security contribution rates on gross labor income") for several levels of country-wide average wages: 67\%, 100\%, 133\%, and $167 \%$. In certain countries, tax rates on wages are highly progressive, e.g., in Finland in 2012, the average tax wedge for $67 \%$ of average income is equal to $36 \%$, whereas for $167 \%$, it increases to $48 \%$. In Poland, the analogous tax wedges are $33.3 \%$ (for $67 \%$ of the average income) and 35\% (for 167\%). These figures are very similar throughout the period 2000-2011. Therefore, in Poland, the size of tax wedge on labor is nearly independent of the level of income, i.e., effective tax rates on wages are nearly linear. Thus, it is reasonable to assume that average tax rates on human capital and raw labor in Poland are identical, i.e., $\tau_{H}=\tau_{L}$.

Recall that according to Eurostat, $\tau_{L}=32.8 \%$. Unfortunately, if we set $\tau_{H}=\tau_{L}=32.8 \%$, and perform the entire calibration as follows, the model significantly overestimates the total revenue from income taxes (by 
approximately 5\% of GDP). Presumably, this problem arises because our (model's) concepts of human capital and raw labor are not identical to the definitions employed by Eurostat. In particular, Eurostat classifies "taxes on income and social contributions of the self-employed" as part of the capital income tax - a detailed explanation can be found in the methodological publication by Eurostat (2010), Annex B. However, self-employed entrepreneurs definitely correspond to our concept of human capital (as well as part of raw labor). Self-employment is very popular in Poland not only are there millions of small, family businesses, but very often individuals operate single-person firms and provide services for larger enterprises. Moreover, the tax rate on capital income published by Eurostat is much lower (21.2\%) than the tax rate on labor (32.8\%). Therefore, in our model, the tax rate on human capital and labor should be somewhere between these two numbers. As there are no additional statistics, we calibrate both rates at this level, for which the model produces a total share of taxes in GDP that is consistent with statistics (32.7\%, see above). In so doing, we obtain $\tau_{H}=\tau_{L}=24.2 \%$, i.e., rates that are approximately $1 / 4$ lower than those reported by Eurostat.

The next step in the calibration is computing the values of expressions $A_{i}$. We do not report these values here, as they do not have any economic interpretation. Knowing these values, and using formula (30), we compute the average capital growth during the period 2000-2011:

$\hat{K}=(1-\psi) A_{2} A_{3} \frac{Y}{K}+A_{4}=2.70 \%$

The average GDP growth rate in Poland during the period 2000-2011 was 3.48\% (geometric mean). Knowing this, we can estimate the human capital growth rate, on the basis of equation (A4), from which it follows that

$\hat{H}=\frac{\hat{Y}-(\alpha+\beta) \hat{K}}{(1-\alpha-\beta)}=\frac{3.48 \%-\frac{2}{3} \cdot 2.70 \%}{1 / 3}=5.04 \%$.

These results suggest that in the period 2000-2011, economic growth in Poland was primarily driven by rapid growth in the stock of human capital and only secondarily by the accumulation of productive capital.

This impressive increase in human capital in Poland is a well-known 'stylized fact' confirmed by numerous indicators concerning education - a sharp increase in the number of students, $\mathrm{PhDs}$, etc. It is worth noting that a $5 \%$ growth rate of human capital implies that its stock doubles in only 15 years.

To perform the calculations (simulations), it is necessary to have an estimate of the value of the parameter $A$. First, from equation (33), we calculate the proportion

$\frac{K}{H}=\frac{\hat{H}+\delta_{H}}{A_{5} Y / K+A_{6}}=3.0371$.

Transforming formula (4) and substituting the above ratio yields

$A=\frac{Y}{K^{\alpha+\beta} H^{1-\alpha-\beta}}=\frac{Y}{K} \cdot\left(\frac{K}{H}\right)^{1-\alpha-\beta}=0.4827$.

To perform the simulations, we should also assume certain initial values of the variables $K, H$ and $L$. Two of them ( $K$ and $L$ ) can be determined completely freely, provided that we confine our interest to the rates of growth and relationships (the proportions) among variables. Therefore, we set $L(0)=1$ and $K(0)=300$. This particular choice is convenient, as the initial level of GDP is then equal to 100, and the initial values of all the other variables are identical to their percentage shares of GDP. From (43), it follows that $H(0)=98.78$.

In summary, we have the following base set of values for the parameters and initial values of the factors of production:

$A=0.4827, \quad \alpha=1 / 3, \quad \beta=1 / 3, \quad \delta_{K}=4 \%, \quad \delta_{H}=1.5 \%$,

$\gamma=25.02 \%, \quad \psi=2.9 \%, \quad \gamma_{E}=5.84 \%, \quad \gamma_{T}=15.5 \%$,

$\tau_{K}=21.2 \%, \tau_{C}=19.4 \%, \tau_{H}=\tau_{L}=24.2 \%, L(0)=1$,

$K(0)=300, H(0)=98.78$.

\section{Baseline scenario}

The baseline set of parameters (45) generates results that precisely correspond to actual statistics on the Polish economy during the period 2000 - 2011. Specifically, the baseline scenario reproduces factual (average) ratios of the following variables to GDP: $C, I_{K}$, $I_{H}, T_{1}, T_{2}, G_{T}, G_{E}$, as well as the (average) rate of GDP growth observed between 2000 and 2011. There is nothing surprising in this -the result is precisely obtained due to the method of calibration. The rates of growth for $t=0$ generated by the model in the baseline scenario are equal to

$\hat{Y}=3.48 \%, \hat{K}=2.70 \%, \hat{H}=5.04 \%$. 


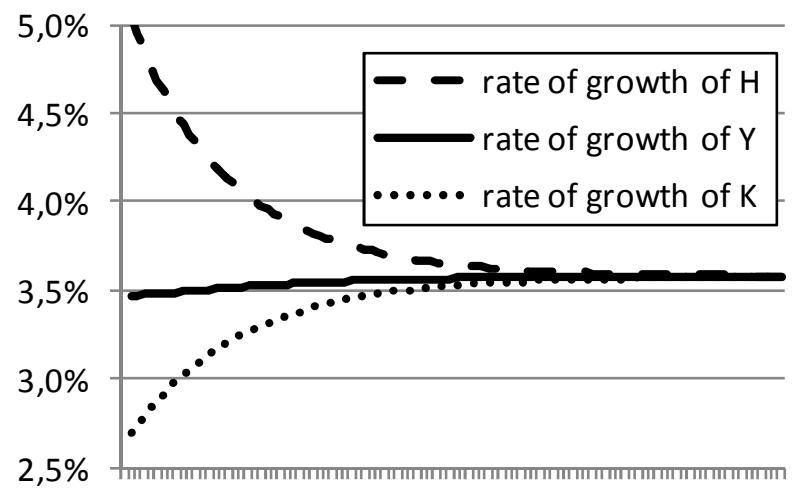

$\begin{array}{lllllllllll}0 & 10 & 20 & 30 & 40 & 50 & 60 & 70 & 80 & 90 & 100\end{array}$

Figure 1. Convergence to the balanced growth path.

These rates are not equal, and hence the Polish economy is not yet on the balanced growth path. By (numerically) solving the equation formed by equating right-hand sides of equations (36) and (37), we obtain the BGR in the baseline scenario. It is equal to $3.58 \%$, slightly higher than the average growth rate recorded during the period 2000-2011. To depict the process of convergence towards the balanced growth path, we present a graph illustrating the trajectories of the above growth rates in the baseline scenario.

\section{Selected tax-cut scenarios in Poland}

Let us determine the effects of reducing various types of taxes in the model calibrated for Poland. We consider 2 types of scenarios:

a) reducing a given tax rate by 1 or 5 percentage points (pp),

b) reducing all tax rates by 1 or $5 \mathrm{pp}$.

Table 2 contains the BGRs calculated under all of these scenarios. In all cases, the economy grows more rapidly (on the balanced growth path) than in the baseline scenario. To better visualize the long-term (welfare) effect of reducing taxes, we also include numbers indicating by how many percent GDP exceeds baseline
GDP after 30 years (in table 2, numbers in bold and italics). These indicators are calculated as follows:

gain after 30 years $=\frac{Y(t=30) \text { in selected scenario }}{Y(t=30) \text { in the baseline scenario }}-1$.

In each scenario, the tax rates are reduced at $t=0$.

Unsurprisingly, the most favorable results are associated with the largest tax cuts, i.e., the scenario of reducing all tax rates by 5 pp. After 30 years, GDP would be $11.9 \%$ higher than under the baseline scenario. Let us analyze this specific scenario in greater depth. Table 3 summarizes selected structural macroeconomic indicators under that scenario, relative to those in the baseline scenario.

After lowering all tax rates by $5 \mathrm{pp}$, the overall tax burden would decline from current $33 \%$ to $26.1 \%$ of GDP, which would be similar to those currently observed in the United States (approx. 25\%), South Korea (26\%) and Japan (27\%). The immediate effect of the reduction in taxes would be an increase in private sector savings relative to GDP (from $20.7 \%$ to $22.4 \%$ ), an increase in investment (from $20 \%$ to $21.7 \%$ of GDP), and finally, a rise in private expenditures on education. The accelerated accumulation of both physical and human capital would shift the economy to a higher balanced 
Table 2. Simulation results for Poland - different scenarios of tax cuts

\begin{tabular}{lcc}
\hline & $\mathbf{1}$ pp reduction & $\mathbf{5}$ pp reduction \\
\hline$\tau_{L}$ & $3.59 \%$ & $3.66 \%$ \\
& $0.5 \%$ & $2.5 \%$ \\
$\tau_{K}$ & $3.59 \%$ & $3.63 \%$ \\
& $0.3 \%$ & $1.6 \%$ \\
$\tau_{H}$ & $3.59 \%$ & $3.66 \%$ \\
& $0.5 \%$ & $2.5 \%$ \\
$\tau_{C}$ & $3.61 \%$ & $3.73 \%$ \\
& $0.9 \%$ & $4.8 \%$ \\
reduction of all tax rates simultaneously & $3.65 \%$ & $3.95 \%$ \\
& $2.2 \%$ & $11.9 \%$ \\
\hline
\end{tabular}

Table 3. The scenario of simultaneously reducing all tax rates by $5 \mathrm{pp}$.

\begin{tabular}{lcc}
\hline the BGR and structural indicators (\%) & baseline scenario & reduction of all tax rates by $\mathbf{5}$ pp \\
\hline the BGR & 3.58 & 3.95 (the effect after 30 years= $+11.9 \%)$ \\
$C / Y$ & 61.9 & 67.0 \\
$T / Y$ & 33.0 & 26.1 \\
$S / Y$ & 20.7 & 22.4 \\
$I_{K} / Y$ & 20.0 & 21.7 \\
$G_{E} / Y$ & 5.8 & 5.8 \\
$I_{H} / Y$ & 0.6 & 0.7 \\
\hline
\end{tabular}

growth path. As a result, the BGR would increase by approximately 0.38 percentage points.

It is worth noting that this scenario is associated with significant structural changes in the economy. Reduced tax receipts, while maintaining a $15.5 \%$ share of cash social transfers in GDP (primarily pensions) and a $5.8 \%$ share of public expenditures on education in GDP, would negatively affect public consumption expenditures, i.e., national defense, public safety, health care, public administration, environmental protection, etc. This gap would have to be (partially) offset by increased consumption spending in the private sector. Thanks to the tax cuts, this would occur naturally.
Under the scenario presented in table 3, the share of private consumption in GDP increases from $61.9 \%$ to $67.0 \%$. Again, this would bring the Polish economy structurally closer to the United States, where private consumption is equal to approximately $70 \%$ of GDP.

\section{Changing the structure of tax revenue}

The scenario of significant tax cuts presented in the previous paragraph would be quite difficult to achieve in practice due to the abovementioned structural changes induced by the reduction in public spending. It is tempting, therefore, to consider 
Table 3. The scenario of simultaneously reducing all tax rates by $5 \mathrm{pp}$.

\begin{tabular}{|c|c|c|c|c|}
\hline $\begin{array}{l}\text { The BGR and } \\
\text { structural } \\
\text { indicators } \\
(\%)\end{array}$ & $\begin{array}{c}\text { Baseline scenario } \\
\begin{array}{c}\gamma_{E}=5,84 \% \\
\gamma=25,02 \% \\
\psi=2,9 \%\end{array}\end{array}$ & $\begin{array}{c}\text { A } \\
\text { Increase in public } \\
\text { spending on education } \\
\text { by } 1 \text { pp of GDP } \\
\gamma_{E}=6,84 \%\end{array}$ & $\begin{array}{c}\text { B } \\
\text { Increase in private } \\
\text { savings by } 1 \text { pp of GDP } \\
\gamma=26,17 \% \\
\psi=2,9 \%\end{array}$ & $\begin{array}{c}\mathrm{C} \\
\text { Increase in private } \\
\text { spending on education } \\
\text { by } 1 \text { pp of GDP } \\
\gamma=26,21 \% \\
\psi=7,47 \%\end{array}$ \\
\hline the $B G R$ & 3,58 & $\begin{array}{c}3,89 \\
\text { GDP effect after } 30 \text { years } \\
+9,4 \%\end{array}$ & $\begin{array}{c}3,80 \\
\text { GDP effect after } 30 \text { years } \\
+6,8 \%\end{array}$ & $\begin{array}{c}3,90 \\
\text { GDP effect after } 30 \text { years } \\
+9,5 \%\end{array}$ \\
\hline$C / Y$ & 61,9 & 61,8 & 61,1 & 61,0 \\
\hline$T / Y$ & 33,0 & 33,0 & 32,8 & 32,9 \\
\hline$S / Y$ & 20,65 & 20,65 & 21,65 & 21,65 \\
\hline$I_{K} / Y$ & 20,04 & 20,04 & 21,01 & 20,04 \\
\hline$G_{E} / Y$ & 5,84 & 6,84 & 5,84 & 5,84 \\
\hline$I_{H} / Y$ & 0,62 & 0,62 & 0,65 & 1,62 \\
\hline
\end{tabular}

alternative scenarios with unchanged levels of taxation (and public spending) but a modified tax structure. Under this scenario, all three income tax rates are reduced by 5 percentage points and the consumption tax rate is increased, and hence the share of taxes in GDP is identical to that in the baseline scenario, i.e., $26.62 \%$ instead of $19.4 \%$. The results of the calculations reveal that such a change in the tax structure would be neutral for the economy. Neither the BGR nor any of structural indicators (listed in table 3) would change. Simply, in our model, the structure of taxes is neutral - the important factor is the level of taxation.

\section{Selected scenarios of increasing public and private spending on education}

In this section, 3 scenarios are presented:

A) the government increases public spending on education by 1 pp of GDP at the expense of public consumption.

B) private sector savings increase by $1 \mathrm{pp}$ of GDP (at the expense of individual consumption), with an unchanged structure of investment expenditures (i.e., an unchanged value of $\psi$ ). As a result, private investment in physical and human capital would increase by a total of $1 \mathrm{pp}$ of GDP.

C) private sector savings increase by $1 \mathrm{pp}$ of GDP (at the expense of individual consumption), but additional savings are spent solely on education. (For this purpose, the value of $\psi$ has been appropriately amended). In other words, private spending on education increases by $1 \mathrm{pp}$ of GDP at the expense of private consumption.

Table 4 presents the results.

With respect to the BGR, all three scenarios significantly outperform the baseline scenario. However, the effect of additional spending on education (scenarios A and C) is stronger than the effect of a similar increase in private savings, with additional resources being primarily spent on investments in physical capital (97\%). These simulations suggest that it is much more preferable to spend additional money on education rather than on physical capital. Moreover, from the comparison of scenarios $\mathrm{A}$ and $\mathrm{C}$, it follows that it is relatively unimportant whether the additional funds for education come from a reduction in public or private consumption. 


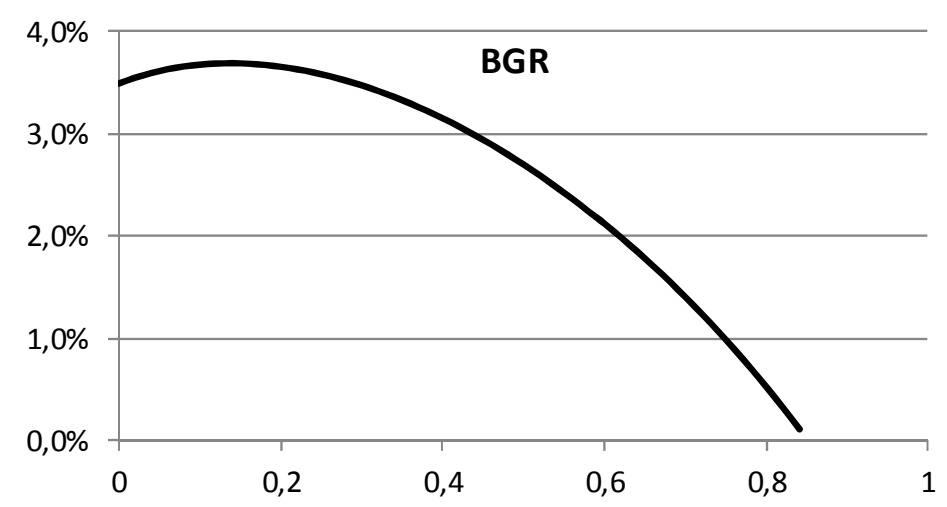

Figure 2.The BGR as a function of the share parameter $\psi$

\section{The optimal structure of private investment}

Clearly, investing in human capital (education) is of crucial importance for economic growth. However, in section 3, we were unable to analytically establish the relationship between the BGR and the share parameter $\psi$ (precisely, the share of private savings spent on education). Now, using the baseline scenario as a benchmark, we can calculate the BGR corresponding to any value of $\psi$ from $0 \%$ to $100 \%$. Figure 2 presents the results. The BGR reaches a maximum (equal to $3.695 \%$ ) at $\psi=14 \%$. According to Eurostat, at present only $3 \%$ of private savings in Poland is spent on education. Therefore, the current structure of private investment in Poland is far from optimal. Households should spend $14 \%$ of their savings on education, rather than only $3 \%$. However, in our view, it appears nearly certain that private spending on education is underestimated in official statistics - a substantial share of it is classified as consumption (e.g., the cost of accommodation, travel, books, etc.).

\section{Summary}

In the long run, the economy is trending toward a dynamic equilibrium, characterized by so-called balanced growth. We demonstrated that the equilibrium is globally asymptotically stable. Despite the simplicity of the model, the balanced growth rate (BGR) can only be calculated numerically, as it requires solving a complex, non-linear equation. On the one hand, the BGR is an increasing function of the rate of private savings, the rate of public transfers, and the rate of public spending on education. On the other hand, the BGR is a decreasing function of tax rates on labor, human capital and consumption. Finally, the relationship between the BGR and the tax rate on capital income, as well as the share coefficient (the percentage of private savings invested in education), is ambiguous. It is important to recall that this ambiguity is a property of the theoretical model and implies that these relationships are dependent on specific parameter values. In other words, the relationship between the tax rate on capital and the BGR can be positive or negative - it depends on the parameter values. Therefore, this question can only be addressed after establishing the values of all parameters - as we do for Poland in the second part of the paper. The central empirical conclusions regarding Poland can be summarized as follows. In the period 2000-2011, economic growth in Poland was primarily driven by a very rapid increase in the stock of human capital (at a rate of 5\% per annum) and only secondarily by the accumulation of productive capital 
(2.7\% annually). Income taxes and consumption taxes restrict economic growth to an equally burdensome extent. Therefore, if the government must collect a certain amount of tax revenue, it is irrelevant what type of tax will be used for that purpose.

Reducing income and consumption tax rates by 5 percentage points in Poland should increase annual GDP growth by approximately 0.4 percentage points, which after 30 years would entail a cumulative effect of a $12 \%$ increase in GDP relative to a scenario assuming current tax rates. Structurally, this scenario would bring the Polish economy closer to such countries as the United States or South Korea, where the tax burden is significantly lower (approximately 25\% of GDP, whereas in Poland it is 33\%) and the share of individual consumption is significantly higher (approximately $70 \%$ of GDP, whereas the figure for Poland is approximately 62\%).

Investing in human capital (education) is crucial to economic growth. An increase in education expenditures by 1 percentage point of GDP would have a similar long-run effect as simultaneously reducing all tax rates by 4 percentage points. The GDP growth rate would increase by approximately 0.3 percentage points. Whether the additional funding for education comes from a reduction in public or private consumption is irrelevant.

At present, households in Poland save approximately $21 \%$ of GDP, but only $3 \%$ of private savings is spent on education, and $97 \%$ is invested in capital. However, the optimal composition of savings, holding all other parameters constant, is approximately $14 \%$ / $86 \%$. Therefore, the current structure of private investment in Poland is far from the optimum. It is possible, however, that private spending on education is underestimated in official statistics - a substantial share of it is likely classified as consumption (e.g., the cost of accommodation, travel, books, etc.).

Despite certain obvious simplifications, our analysis provides qualitative and quantitative insights into the negative effects of taxes and positive influence of education on economic growth in Poland. It appears to capture certain important 'stylized facts', especially the rapid accumulation of human capital over the past 20 years. Nevertheless, one should recall that our model neglects certain important, though transitory, factors of growth. For example, over the past decade, Poland experienced large inflows of foreign capital, in the form of both FDI and portfolio investment. However, a significant migration of young persons from Poland to other EU countries was observed. The growth effects of these two phenomena remain under investigation, but it is reasonable to contend that they offset one another out to some extent.

\section{References}

Acemoglu, D. (2008). Introduction to Modern Economic Growth. Princeton, NJ: Princeton University Press.

Agenor, P. R. (2007). Fiscal policy and endogenous growth with public infrastructure. Oxford Economic Papers, 60 (1), 57-87.

Arrazola, M., de Hevia, J. (2004). More on the estimation of the human capital depreciation rate. Applied Economic Letters, 11 (3), 145-148.

Balistreri, E. J., McDaniel, C. A., Wong, E. V. (2003). An estimation of US industry-level capital-labor substitution elasticities: support for Cobb-Douglas. The North American Journal of Economics and Finance, 14 (3), 343-356.

Barro, R. J. (1990). Government spending in a simple model of economic growth. Journal of Political Economy, 98 (5), 103-125.

Barro, R. J., Sala-i-Martin, X. (2004). Economic Growth (2nd ed.). Cambrigde, MA: MIT Press

Campbell, J., Diamond, P., \& Shoven, J. (2001). Estimating the Real Rate of Return on Stocks Over the Long Term. Social Security Advisory Board, Washington. Retrieved from: http://www.ssab.gov/publications/ financing/estimated\%20rate\%20of\%20return.pdf

Cichy, K. (2008). Kapitał ludzki i postęp techniczny jako determinanty wzrostu gospodarczego [Human capital and technological progress as determinants of economic growth]. Warsaw: Instytut Wiedzy i Innowacji.

Dhont, T., Heylen, F. (2009). Employment and growth in Europe and the US - the role of fiscal policy composition. Oxford Economic Papers, 61 (3), 538-565.

Elmendorf, D. W., Mankiw, N. G. (1998). Government Debt (Working Papers No. 6470). National Bureau of Economic Research.

Eurostat (2010). Taxation trends in the European Union - Data for the EU Member States, Iceland and Norway. Luxembourg: Publications Office of the European Union. Retrieved from: http://ec.europa. eu/taxation_customs/resources/documents/ taxation/gen_info/economic_analysis/tax_structures/2010/2010_full_text_en.pdf 
Gordon, K., Tchilinguirian, H. (1998). Marginal Effective Tax Rates on Physical, Human and R\&D Capital (Working Papers No. ECO/WKP(98)12). OECD Economic Department.

Heckman, J. J., Jacobs, B. (2010). Policies to Create and Destroy Human Capital in Europe (Working Papers No. 15742). National Bureau of Economic Research.

Konopczyński, M. (2013). Fiscal policy within a common currency area - growth implications in the light of neoclassical theory. Contemporary Economics, 7 (3), 5-16.

Lee, Y., Gordon, R. (2005). Tax structure and economic growth. Journal of Public Economics, 89 (5-6), 1027-1043.

Mankiw, G. N., Romer, D., \& Weil, D. N. (1992). A Contribution to the Empirics of Economic Growth. Quarterly Journal of Economics, 107 (2), 407-437.

Manuelli, R., Seshadri, A. (2005). Human Capital and the Wealth of Nations (Meeting Papers No. 56). Society for Economic Dynamics.

Nehru, V., Dhareshwar, A. (1993). A new database on physical capital stock: sources, methodology and results. Revista de análisis económico, 8 (1), 37-59.

Próchniak, M. (2013). To What Extent Is the Institutional Environment Responsible for Worldwide Differences in Economic Development. Contemporary Economics, 7(3), 17-38.

Romer, P. M. (1986). Increasing returns and long-run growth. Journal of Political Economy, 94 (5), 10021037.

Turnovsky, S. J. (2009). Capital Accumulation and Economic Growth in a Small Open Economy. Cambridge, UK: Cambridge University Press.

Willman A. (2002). Euro Area Production Function and Potential Output: A Supply Side System Approach (Working Papers No. 153). European Central Bank. 


\section{Appendix}

\section{Proof of Proposition 1.}

Dividing both sides of equation (11) by $K$ and substituting (9), we obtain a formula for the growth rate of productive capital:

$\hat{K}=\frac{\dot{K}}{K}=(1-\psi) \gamma \frac{Y}{K}-\delta_{K}$,

Similarly, by dividing both sides of equation (12) by $H$ and substituting (10), we obtain a formula for the rate of human capital growth:

$\hat{H}=\frac{\dot{H}}{H}=\psi \gamma \frac{Y}{H}-\delta_{H}$,

By assumption, $\psi \in(0 ; 1)$ and $\gamma \in(0 ; 1)$. Thus, if $\hat{K}<\hat{Y}$, then capital grows more slowly than output, and consequently, the ratio $Y / K$ increases over time, which according to (A1) implies that $\hat{K}$ also increases over time. Conversely, if $\hat{K}>\hat{Y}$, then capital grows more rapidly than output, and hence the ratio $Y / K$, as well as $\hat{K}$, will decrease over time. Therefore, from equation (A1), it follows that over time, the economy is converging toward a balanced state, in which $\hat{K}=\hat{Y}$. A similar conclusion follows from equation (A2): with the passage of time, the economy is converging toward the balanced state, in which $\hat{H}=\hat{Y}$. Therefore, in the long term, the economy converges toward the balanced growth path, on which the following equality holds:

$\hat{K}=\hat{H}=\hat{Y}$,

From equations (A1) and (A2), if follows directly that there exists exactly one such equilibrium (it is unique), and it is globally asymptotically stable. To determine the equilibrium, one must solve the system of equations (A3). First, note that from the equation (4), it follows that:

$\hat{Y}=(\alpha+\beta) \hat{K}+(1-\alpha-\beta) \hat{H}$,

Thus, if $\hat{K}=\hat{H}$, then $\hat{K}=\hat{H}=\hat{Y}$, and hence the system of equations (A3) can be reduced to a single equation: $\hat{K}=\hat{H}$. Unfortunately, except for certain special cases, this equation cannot be solved analytically. To see why, let us use equation (4) to write growth rates (A1) and (A2) in the following equivalent form:

$$
\begin{aligned}
& \hat{K}=(1-\psi) \gamma A\left(\frac{K}{H}\right)^{\alpha+\beta-1}-\delta_{K}, \\
& \hat{H}=\psi \gamma A\left(\frac{K}{H}\right)^{\alpha+\beta}-\delta_{H},
\end{aligned}
$$

We can treat the ratio $K / H$ as a single variable (the unknown). Then, from (A5) and (A6), it follows that the equation $\hat{K}=\hat{H}$ can only be solved numerically, after substituting certain values for all parameters. (Only in special cases can this equation be solved analytically. For example, if we set $\alpha=\beta=1 / 3$, then this equation can be transformed into a polynomial equation of the fourth degree and solved analytically.) Nevertheless, it is possible to "solve" it graphically, by graphing the right-hand sides of equations (A5) and (A6). Strictly speaking, we graph the rates of growth $\hat{K}$ and $\hat{H}$ as functions of $K / H$. It is easy to show that the function $\hat{K}(K / H)$ is decreasing and strictly convex. Moreover, $\hat{K} \underset{K / H \rightarrow 0^{+}}{\longrightarrow}+\infty$, and $\hat{K} \underset{K / H \rightarrow+\infty}{\longrightarrow}-\delta_{K}$. However, the function $\hat{H}(K / H)$ is increasing, strictly concave, $\hat{H}(K / H=0)=-\delta_{H}$, and $\hat{H} \underset{K / H \rightarrow+\infty}{\longrightarrow}+\infty$. The graphs of these functions are illustrated in figure A1. Due to the properties of these functions, there is exactly one point of intersection, i.e., there exists exactly one ratio $\bar{K} / \bar{H}$ for which $\hat{K}=\hat{H}$. The values of both functions at this point determine the balanced growth rate (the BGR).

Figure A1 also indicates that the balanced state is globally asymptotically stable. Notice that to the left of the point of intersection of the graphs, $\hat{K}>\hat{H}$, and hence over time, $K / H$ increases, which implies that with the passage of time, the economy moves to the right. However, to the right of the point of intersection of the graphs, $\hat{K}<\hat{H}$, and hence over time, $K / H$ decreases, which implies that with the passage of time, the economy moves to the left. (The direction of motion is illustrated by the arrows in fig. A1.)

Notice that an increase in the value of the parameter $\gamma$ and/or a decrease in the value of $\delta_{K}$ shifts the graph of the function $\hat{K}(K / H)$ upwards. Similarly, an increase in the value of the parameter $\gamma$ and/or a decrease in the value of $\delta_{H}$ shifts the graph of the function $\hat{H}(K / H)$ upwards. Thus, the BGR is an increasing function of $\gamma$ and, simultaneously, a decreasing function of both rates of depreciation.

However, when the share parameter $\psi$ increases, the graph of $\hat{K}(K / H)$ shifts up, but the graph of $\hat{H}(K / H)$ simultaneously shifts down. Therefore, the 


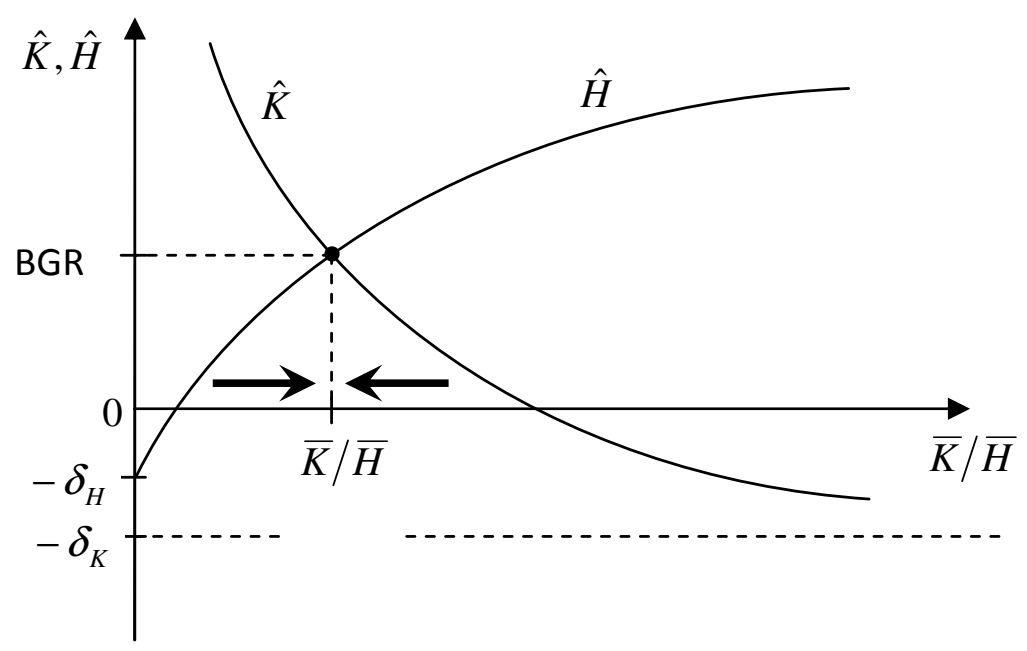

Figure A1. Graphs of the functions $\hat{K}(K / H)$ and $\hat{H}(K / H)$ in the private economy

relationship between the BGR and $\psi$ is ambiguous. It can only be established numerically, after substituting values for all parameters.

\section{Proof of Proposition 2.}

First, let us determine the signs of all expressions that are marked with symbols $A_{i}$. Under the assumptions adopted regarding the signs and the values of tax rates, rates of savings, and other parameters, it can easily be shown that:

$$
A_{2}, A_{3}, A_{5}, A_{6}>0, A_{4}<0 \text { and } A_{2}<1, A_{6}<1 \text {, }
$$

Similarly as above, let us graph the rates of growth $\hat{K}$ and $\hat{H}$ given by (36) and (37) as the functions of $K / H$. Using (A7) it is easy to prove that the function $\hat{K}(K / H)$ is decreasing and strictly convex. Moreover, $\hat{K} \underset{K / H \rightarrow 0^{+}}{\longrightarrow}+\infty$, and $\hat{K} \underset{K / H \rightarrow+\infty}{\longrightarrow} A_{4}$. However, the function $\hat{H}(K / H)$ is increasing, strictly concave, $\hat{H}(K / H=0)=-\delta_{H}$, and $\hat{H} \underset{K / H \rightarrow+\infty}{\longrightarrow}+\infty$. The graphs of these functions are illustrated in figure A2. Due to the properties of these functions, there is exactly one point of intersection, i.e., there exists exactly one ratio $\bar{K} / \bar{H}$ for which $\hat{K}=\hat{H}$. The values of both functions at this point determine the balanced growth rate (the BGR). The balanced state is globally asymptotically stable, which is illustrated in figure A2. In equilibrium $\hat{K}=\hat{H}$, which together with (4), implies that $\hat{Y}=\hat{K}=\hat{H}$.

\section{Sensitivity of the results to the $K / Y$ ratio}

Due to lack of suitable statistics, the ratio of $K / Y$ for Poland was calibrated based on the average value for 22 OECD countries, which is equal to 3.0. However, in certain OECD countries, the $K / Y$ ratio is higher, while it is lower in others. This section presents the most important results of the paper; we set the ratio of $K / Y$ for Poland at the level of 3.3 or 2.7, instead of 3.0 (as we do in the main text). Tables $2 \mathrm{~A}-4 \mathrm{~A}$ are the counterparts of tables $2-4$ if we set $K / Y=3.3$. Similarly, tables $2 \mathrm{~B}-4 \mathrm{~B}$ are the counterparts of tables $2-4$ if we set $K / Y=2.7$. The general conclusion is that the results are very insensitive to the initial value of $K / Y$. All welfare gains - as measured by the GDP effect after 30 years - are very similar to the results obtained in the main text. 


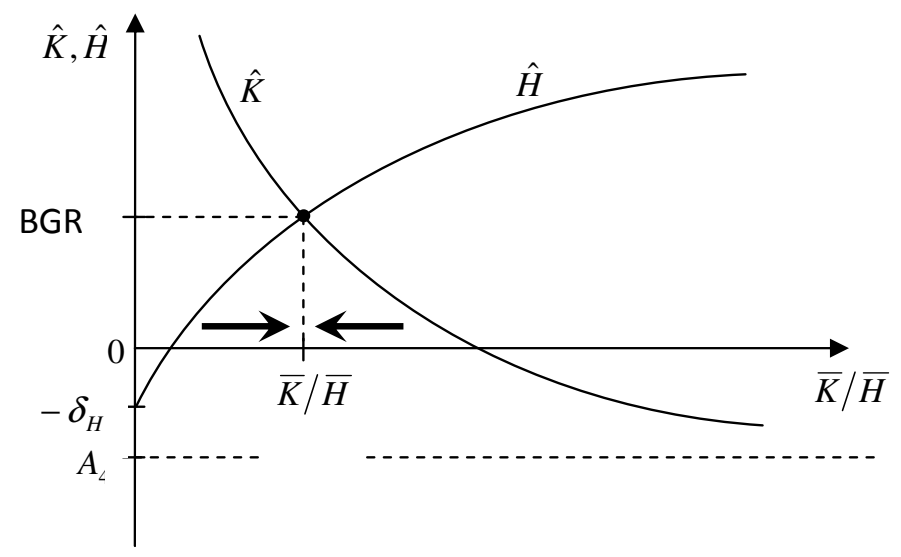

Figure A2. Graphs of the functions $\hat{K}(K / H)$ and $\hat{H}(K / H)$ in the economy with the government

Table 2A. Simulation results for Poland - different tax-cut scenarios, $K / Y=3.3$.

\begin{tabular}{lcc}
\hline & 1 pp reduction & 5 pp reduction \\
\hline$\tau_{L}$ & $3.54 \%$ & $3.60 \%$ \\
& $0.5 \%$ & $2.4 \%$ \\
$\tau_{K}$ & $3.53 \%$ & $3.58 \%$ \\
& $0.3 \%$ & $1.5 \%$ \\
$\tau_{H}$ & $3.54 \%$ & $3.60 \%$ \\
& $0.5 \%$ & $2.4 \%$ \\
$\tau_{C}$ & $3.55 \%$ & $3.68 \%$ \\
& $0.9 \%$ & $4.6 \%$ \\
reduction of all tax rates simultaneously & $3.60 \%$ & $3.90 \%$ \\
\end{tabular}

Table 2A. The scenario of simultaneously reducing all tax rates by $5 \mathrm{pp}, K / Y=3.3$.

\begin{tabular}{ccc}
\hline the BGR and structural indicators $(\%)$ & baseline scenario & reduction of all tax rates by $\mathbf{5}$ pp \\
\hline the $B G R$ & 3.52 & 3.90 (the effect after 30 years $=+11.6 \%)$ \\
$C / Y$ & 61.7 & 66.9 \\
$T / Y$ & 33.2 & 26.3 \\
$S / Y$ & 20.6 & 22.3 \\
$I_{K} / Y$ & 20.0 & 21.6 \\
$G_{E} / Y$ & 5.8 & 5.8 \\
$I_{H} / Y$ & 0.6 & 0.7 \\
\hline
\end{tabular}


Table 4A. Scenarios of increasing public and private spending on education, $K / Y=3.3$

\begin{tabular}{|c|c|c|c|c|}
\hline $\begin{array}{c}\text { The BGR and structural } \\
\text { indicators } \\
(\%)\end{array}$ & $\begin{array}{c}\text { Baseline scenario } \\
\gamma_{E}=5.84 \% \\
\gamma=25.02 \% \\
\psi=2.9 \%\end{array}$ & $\begin{array}{c}\text { A } \\
\text { Increase in public } \\
\text { spending on education } \\
\text { by } 1 \text { pp of GDP } \\
\gamma_{E}=6.84 \%\end{array}$ & $\begin{array}{c}\text { B } \\
\text { Increase in private } \\
\text { savings by } 1 \text { pp of GDP } \\
\gamma=26.17 \% \\
\psi=2.9 \%\end{array}$ & $\begin{array}{c}\text { C } \\
\text { Increase in private } \\
\text { spending on education } \\
\text { by } 1 \text { pp of GDP } \\
\gamma=26.21 \% \\
\psi=7.47 \%\end{array}$ \\
\hline the $B G R$ & 3.52 & $\begin{array}{c}3.84 \\
\text { GDP effect } \\
\text { after } 30 \text { years } \\
+9.8 \%\end{array}$ & $\begin{array}{c}3.74 \\
\text { GDP effect } \\
\text { after } 30 \text { years } \\
+6.6 \%\end{array}$ & $\begin{array}{c}3.84 \\
\text { GDP effect } \\
\text { after } 30 \text { years } \\
+9.9 \%\end{array}$ \\
\hline$C / Y$ & 61.7 & 61.7 & 60.9 & 60.8 \\
\hline$T / Y$ & 33.2 & 33.3 & 33.0 & 33.1 \\
\hline$S / Y$ & 20.6 & 20.6 & 21.6 & 21.6 \\
\hline$I_{K} / Y$ & 20.0 & 20.0 & 21.0 & 20.0 \\
\hline$G_{E} / Y$ & 5.84 & 6.84 & 5.84 & 5.84 \\
\hline$I_{H} / Y$ & 0.62 & 0.62 & 0.65 & 1.62 \\
\hline
\end{tabular}

Table 2B. Simulation results for Poland - different tax-cut scenarios, $\boldsymbol{K} / \boldsymbol{Y}=2.7$.

\begin{tabular}{lcc}
\hline & $\mathbf{1}$ pp reduction & $\mathbf{5}$ pp reduction \\
\hline$\tau_{L}$ & $3.50 \%$ & $3.57 \%$ \\
& $0.5 \%$ & $2.5 \%$ \\
$\tau_{K}$ & $3.50 \%$ & $3.54 \%$ \\
& $0.3 \%$ & $1.7 \%$ \\
$\tau_{H}$ & $3.50 \%$ & $3.57 \%$ \\
& $0.5 \%$ & $2.5 \%$ \\
$\tau_{C}$ & $3.52 \%$ & $3.64 \%$ \\
& $0.9 \%$ & $4.8 \%$ \\
reduction of all tax rates simultaneously & $3.56 \%$ & $3.86 \%$ \\
\hline
\end{tabular}

Table 3B. The scenario of simultaneously reducing all tax rates by $5 \mathrm{pp}, \boldsymbol{K} / \boldsymbol{Y}=2.7$.

\begin{tabular}{ccc}
\hline the BGR and structural indicators $(\%)$ & baseline scenario & reduction of all tax rates by $\mathbf{5}$ pp \\
\hline the $B G R$ & 3.49 & 3.86 (the effect after 30 years $=+12.1 \%)$ \\
$C / Y$ & 62.1 & 67.2 \\
$T / Y$ & 32.7 & 25.8 \\
$S / Y$ & 20.7 & 22.4 \\
$I_{K} / Y$ & 20.1 & 21.8 \\
$G_{E} / Y$ & 5.84 & 5.84 \\
$I_{H} / Y$ & 0.62 & 0.67 \\
\hline
\end{tabular}


Table 4B. Scenarios of increasing public and private spending on education, $\boldsymbol{K} / \boldsymbol{Y}=2.7$.

\begin{tabular}{|c|c|c|c|c|}
\hline $\begin{array}{c}\text { The BGR and structural } \\
\text { indicators } \\
(\%)\end{array}$ & $\begin{array}{c}\text { Baseline scenario } \\
\gamma_{E}=5.84 \% \\
\gamma=25.02 \% \\
\psi=2.9 \%\end{array}$ & $\begin{array}{c}\text { A } \\
\text { Increase in public } \\
\text { spending on education } \\
\text { by } 1 \text { pp of GDP } \\
\gamma_{E}=6.84 \%\end{array}$ & $\begin{array}{c}\text { B } \\
\text { Increase in private } \\
\text { savings by } 1 \text { pp of GDP } \\
\gamma=26.17 \% \\
\psi=2.9 \%\end{array}$ & $\begin{array}{c}\mathrm{C} \\
\text { Increase in private } \\
\text { spending on education } \\
\text { by } 1 \text { pp of GDP } \\
\gamma=26.21 \% \\
\psi=7.47 \%\end{array}$ \\
\hline the $B G R$ & 3.49 & $\begin{array}{c}3.80 \\
\text { GDP effect after } 30 \\
\text { years }+8.6 \%\end{array}$ & $\begin{array}{c}3.70 \\
\text { GDP effect after } 30 \\
\text { years }+6.9 \%\end{array}$ & $\begin{array}{c}3.81 \\
\text { GDP effect after } 30 \\
\text { years }+8.8 \%\end{array}$ \\
\hline$C / Y$ & 62.1 & 62.0 & 61.3 & 61.2 \\
\hline$T / Y$ & 32.7 & 32.8 & 32.5 & 32.6 \\
\hline$S / Y$ & 20.7 & 20.70 & 21.7 & 21.7 \\
\hline$I_{K} / Y$ & 20.1 & 20.1 & 21.1 & 20.1 \\
\hline$G_{E} / Y$ & 5.84 & 6.84 & 5.84 & 5.84 \\
\hline$I_{H} / Y$ & 0.62 & 0.62 & 0.65 & 1.62 \\
\hline
\end{tabular}


